\title{
к chain monoallelic demethylation and the establishment of allelic exclusion
}

\author{
Raul Mostoslavsky, ${ }^{1}$ Nandita Singh, ${ }^{3}$ Andrei Kirillov, ${ }^{1}$ Roberta Pelanda, ${ }^{4}$ Howard Cedar, ${ }^{2,6}$ \\ Andrew Chess, ${ }^{3,5}$ and Yehudit Bergman ${ }^{1}$ \\ ${ }^{1}$ The Hubert H. Humphrey Center for Experimental M edicine and Cancer Research, and ${ }^{2}$ Department of Cellular \\ Biochemistry, The Hebrew University Hadassah M edical School, Jerusal em 91120, Israel; ${ }^{3}$ Whitehead Institute \\ for Biomedical Research, Nine Cambridge Center, Cambridge, M assachusetts 02142 USA; ${ }^{4} \mathrm{M}$ ax-Planck Institute \\ for Immunobiology, Freiburg, Germany 79108; ${ }^{5}$ Department of Biology, M assachusetts Institute of Technology, \\ Cambridge, Massachusetts 02139 USA
}

\begin{abstract}
Allelic exclusion in $\kappa$ light-chain synthesis is thought to result from a feedback mechanism by which the expression of a functional $\kappa$ light chain on the surface of the $B$ cell leads to an intracellular signal that down-regulates the $V(D)$ recombinase, thus precluding rearrangement of the other allele. Whereas such a feedback mechanism clearly plays a role in the maintenance of allelic exclusion, here we provide evidence suggesting that the initial establishment of allelic exclusion involves differential availability of the two $\kappa$ alleles for rearrangement. Analysis of $\kappa^{+} B$-cell populations and of individual $\kappa^{+} B$ cells that have rearranged only one allele demonstrates that in these cells, critical sites on the rearranged allele are unmethylated, whereas the nonrearranged allele remains methylated. This pattem is apparently generated by demethylation that is initiated at the small pre-B cell stage, on a single allele, in a process that occurs prior to rearrangement and requires the presence in cis of both the intronic and $3^{\prime} \kappa$ enhancers. Taken together with data demonstrating that undermethylation is required for rearrangement, these results indicate that demethylation may actually underly the process of allelic exclusion by directing the initial choice of a single $\kappa$ allele for rearrangement.
\end{abstract}

[Key Words: Methylation; allelic exclusion; immunoglobulin; B lymphocytes]

Received January 29, 1998; revised version accepted A pril 13, 1998.

The generation of the vast repertoire of antibody molecules during B-cell differentiation is complex and is based on a program of gene-specific rearrangement events (for review, see Lewis 1994; Rajewsky 1996). UItimately, this program leads to the expression of a single heavy chain $(\mu)$ and a single light chain (either $\kappa$ or $\lambda$ ) in each mature B cell. All of these rearrangement events are mediated by conserved recombination signal sequences (RSSs) on the DNA and are carried out by a single set of enzymes (RAG-1 and RAG-2) (Schatz et al. 1989; Oettinger et al. 1990; for review, see Gel lert 1996). In spite of the sharing of the enzymes and RSSs, recombination takes place in a programmed, sequential manner that involves the ordered selection of the proper gene loci as well as a mechanism for choosing only one allele at a time. This poses an interesting problem in the regulation of the rearrangement process.

$M$ any studies of the regulation of rearrangement have focused on the mechanisms underlying the ordered selection of the proper gene loci. These studies have identified enhancer-mediated changes in chromatin struc-

${ }^{6}$ Corresponding author.

E-MAIL cedar@md2.huji.ac.il; FAX 972-2 641-5848. ture as well as changes in the extent of DNA methylation. At various stages of B-cell development, different trans-acting proteins clearly are involved in rendering the $\mu, \kappa$, and $\lambda$ immunoglobulin loci available to the recombination apparatus. Responding to these trans-acting proteins, enhancers and other cis-regulatory se quences mediate local changes in chromatin structure that underlie increased accessibility to the recombinase (Stanhope-Baker et al. 1996). For example, experiments in transgenic mice have clearly shown that enhancer elements can indeed mediate changes in chromatin structure (Jenuwein et al. 1993; Forrester et al. 1994), and in vivo targeted deletions of these sequences strongly repress rearrangement (Chen et al. 1993; Serwe and Sablitzky 1993; Takeda et al. 1993; Xu et al. 1996; Gorman et al. 1996).

DN A methylation plays an important role in regulating transcription and chromatin structure in a number of genes (for review, see M ostoslavsky and Bergman 1997). Methylation has al so been correlated with immunoglobulin gene expression; both the $\mu$ and $\kappa$ chains have been shown to be heavily modified in most tissues, but unmethylated in mature B cells (Mather and Perry 1983; Storb and Arp 1983; Kelley et al. 1988; Goodhardt et al. 1993). Using a transfection assay, we previously demon- 
strated that this pattern is brought about by stage-specific demethylation events that are di rected by local cisacting elements. Demethylation of sequences adjacent to the $J_{\kappa}$ region, for example, can be induced by the presence in cis of a complex DNA signal containing enhancer and matrix attachment region (MAR) sequence elements (Lichtenstein et al. 1994). Additional ly, in vitro experiments have demonstrated that methylation inhibits rearrangement (Engler et al. 1991; Hsieh and Lieber 1992). These experiments suggest an important role for demethylation in the regulation of $\kappa$ gene rearrangement. However, the in vivo role of demethylation in the process of B-cell development has not yet been clarified.

Until now, the random choice of one allele for rearrangement (at a given locus) has not been addressed in studies of chromatin structure or methylation, but rather in experiments that have demonstrated the existence of a feedback mechanism by which the expression of a functional $\kappa$ light chain on the surface of the B cell leads to an intracellular signal that down-regulates the $\mathrm{V}(\mathrm{D})$ J recombinase, thus precluding rearrangement of the other allele. The widely accepted theory is that (for a given immunogl obulin gene locus: $\mu, \kappa$, or $\lambda$ ) inefficiency in the rearrangement process allows one allele to rearrange prior to the other (Coleclough et al. 1981). Then, allelic exclusion results from the feedback down-regulation mechanism discussed above. Whereas such a feedback mechanism clearly plays a role in the maintenance of allelic exclusion, here we provide evidence suggesting that the initial establishment of allelic exclusion involves differential availability of the two $\kappa$ alleles for rearrangement. We demonstrate that demethylation of the $\kappa$ gene occurs initially on only one allele in each $B$ cell. We also define two other aspects of the allele-specific demethylation that are critical to its role in allelic exclusion by demonstrating that, in vivo, demethylation takes place prior to and independently of rearrangement. We al so demonstrate that the demethylati on is driven, in vivo, by the intronic and 3' enhancer sequences that were implicated previously (Lichtenstein et al. 1994; Kirillov et al. 1996) in driving the process in cell lines. These results, when taken together with direct experiments demonstrating that methylation inhibits rearrangement (Engler et al. 1991; Hsieh and Lieber 1992), suggest that demethylation itself may be the rate-limiting step in the rearrangement process. Thus, our results strengthen the model in which changes in DNA methylation play a major role in controlling the program of sequential rearrangement events. Additionally, our data indicating that the demethylation is monoallelic in individual $B$ cells suggest a novel primary basis for allelic exclusion.

\section{Results}

Allelic differences in Ig gene methylation status in normal B cells

To evaluate Igк methylation patterns in vivo, к-expressing $B$ cells were isolated from adult mouse bone marrow or spleen and their DNA was subjected to methylation analysis (see map, Fig. 1). DNA was first digested with HindlII, which allows one to visualize both the germline (discrete 2.7-kb band) and rearranged alleles. Further digestion with the methyl-sensitive restriction enzyme $\mathrm{H}$ hal revealed that (in a large fraction of DN A molecules) sites located in the junction $(J)$ region upstream of the intronic enhancer are unmethylated, whereas the germline band is mostly methylated (Fig. 1a, lanes 1,2). N ext, we examined a 1.0-kb BgllI-HindlII restriction fragment at the $3^{\prime}$ end of the $\mathrm{J}$ cluster that is present in both rearranged and germ-line $\kappa$ alleles. Analysis with $\mathrm{Hhal}$ showed clearly that $~ 50 \%$ of the gene copies are indeed unmethylated (Fig. 1a, lanes 3,4).

To further assess the relationship between $\kappa$ chain gene rearrangement and methylation, $\mathrm{\kappa}^{+} \mathrm{B}$-cell DN A was anal yzed using several different methyl-sensitive restriction enzymes (see map). The unrearranged germ-line copies (2.7-kb Hind III band) are strikingly resistant to digestion at five individual $\mathrm{CPG}$ sites, indicating that most of these molecules are highly methylated (Fig. 1b). In contrast, the rearranged HindlII-treated $\kappa$ allel es, extracted from the smear region $(>2.7 \mathrm{~kb})$ on the original agarose gel (Fig. 1a, lane 1) and further digested with methyl-sensitive restriction enzymes, proved to be compl etely unmethylated over the entire $\mathrm{J} \kappa$ and intronic region (Fig. 1c). This is most clearly seen in the complete digestion by both Sacll and Hhal of the 1.0-kb BglllHindIII fragment (Fig. 1c, lanes 1-3). Methyl sensitivity is also observed in the Hhal site near J4 where most of the 0.6-kb Avall band disappears upon Hhal digestion (Fig. 1c, lanes 4,5). These results demonstrate the presence of rearranged unmethylated alleles and germ-line methylated alleles in $\kappa^{+} B$ cells. Since each cell expresses $\kappa$ light-chain protein on its surface, each must have at least one rearranged $\kappa$ allele. Thus, these experiments demonstrate clearly that in a majority of $\kappa^{+} \mathrm{B}$ cells, a fully methylated germ-line copy coexists with an undermethylated, productively rearranged $\kappa$ allele.

\section{Single-cell analysis of allelic differences in Igк gene} methylation

We have developed an assay to directly determine the methylation status of the two $\kappa$ alleles present in individual $\kappa^{+} B$ cells. In order to accomplish this we first isolated the Mus spretus $\kappa$ gene and identified polymorphisms with respect to the Mus musculus al lele (C57BL/ 6). Thus, in $F_{1}$ progeny from a cross between $M$. spretus and $M$. musculus, it is possible to distinguish the two alleles. Spleen cells were harvested from $F_{1}$ progeny and $\mathrm{K}^{+} \mathrm{B}$ lymphocytes were sorted as single cel Is directly into PCR tubes using a fluorescence-activated cell sorter (FACS). Genomic DN A from these single cells was subjected to digestion by the methyl-sensitive restriction enzyme Aval to analyze the methylation status of the Aval site in J4 (Fig. 2a). After Aval digestion, oligonucleotide primers flanking the Aval site were used for nested PCR (primers 1-4; see Fig. 2a). Because these primers will not amplify DNA that has been Aval di- 


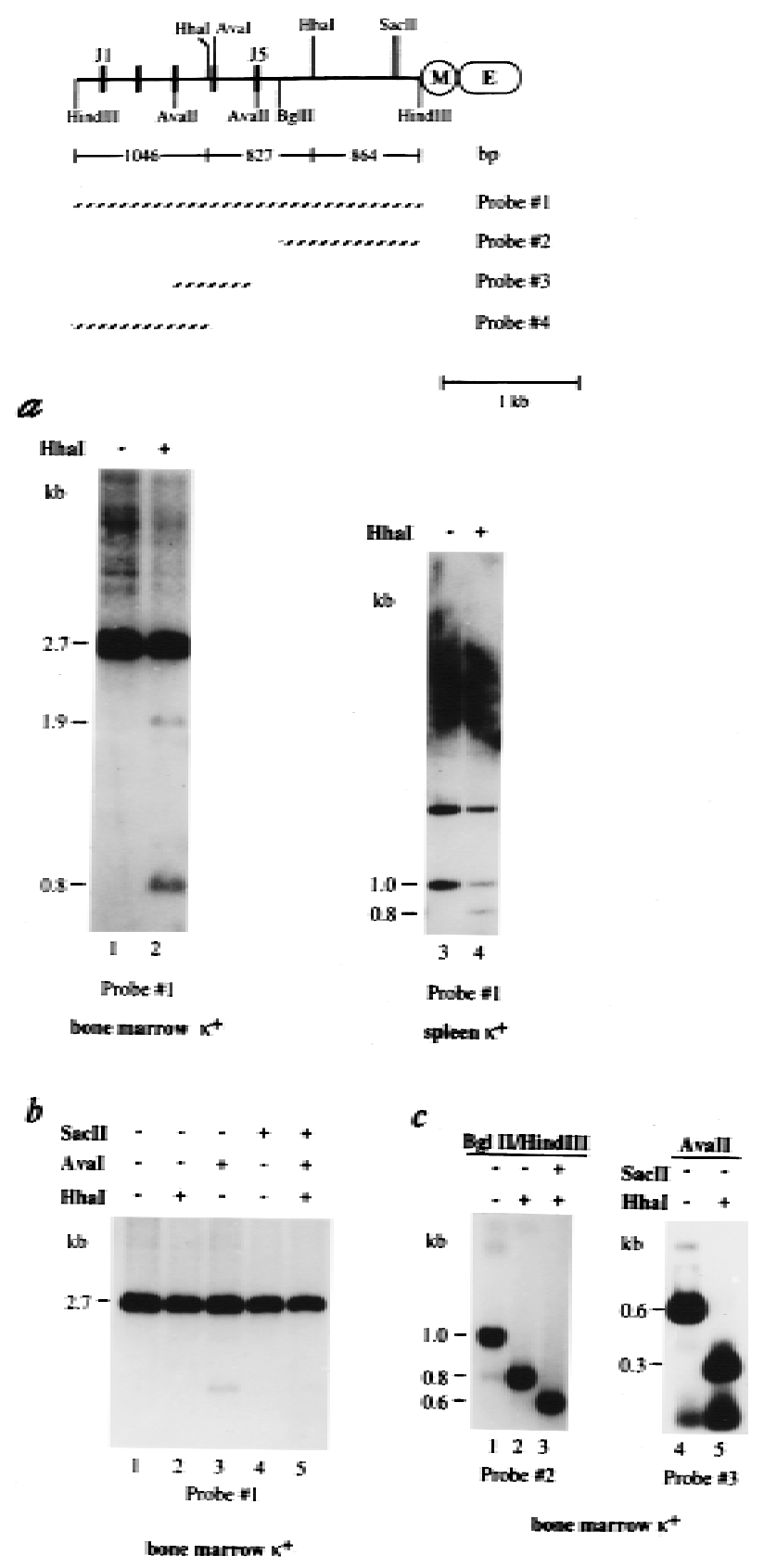

Figure 1. In vivo methylation pattern of the $\kappa$ chain gene. A map of the $\kappa$ chain gene locus shows the J segments, the intronic MAR (M) and enhancer $(E)$ sequences, the relevant restriction sites, fragment sizes, and the probes used in these experiments. (a) DN A from bone marrow (lanes 1,2) or spleen (lanes 3,4$) \kappa^{+}$cells derived from wildtype mice was digested with HindlII (lanes 1-2) or HindlII-BgllI (lanes 3-4) and then tested for methylation by additional restriction with Hhal (+). These samples were then subjected to gel el ectrophoresis and analyzed by blot hybridization using probe 1 . It should be noted that equal amounts of DN A were loaded in both lanes 1 and 2 as indicated by ethidium bromide staining (data not shown). When cut with HindlII the bone marrow DN A shows a germ-line band $(2.7 \mathrm{~kb})$ as well as numerous rearranged bands (seen as a smear). Full undermethylation results in 1046-, 827-, and 864-bp fragments, but partial digests can al so be seen on the gel $(1.6$ and $1.9 \mathrm{~kb})$. It should be noted that the appearance of a $1.9-\mathrm{kb}$ band indicates that a small fraction of the germ-line allele is also unmethylated at some sites. Similar results were seen when DNA from $\mathrm{\kappa}^{+}$spleen cells was analyzed in the same manner (data not shown). Digestion with HindllI-BgllI concentrates all $\kappa$ gene copies into a single band $(1.0 \mathrm{~kb})$, which if unmethylated is reduced to $0.8 \mathrm{~kb}$ when cleaved with $\mathrm{Hhal}$. This site is $\sim 50 \%$ methylated in normal $\mathrm{\kappa}^{+}$cells (lane 4 ). In this gel, the $1.0-\mathrm{kb}$ band has a lower intensity than the 1.7-kb band, mainly because it hybridizes to a smaller part of the probe and because gel transfer is not as efficient at this molecular weight (as shown by analysis of HindlII-BgllI digests of non-B-cell DNA). The upper (1.7-kb) band seen in this gel represents the $5^{\prime}$ HindIII-BgllI fragment derived from germ-line copies of the gene. (b) DNAs from $\mathrm{\kappa}^{+}$bone marrow cells were treated with HindlII and further digested with the methyl-sensitive restriction enzymes, Hhal, Aval, or Sacll and analyzed as in a. (c) Because the degree of undermethylation on the rearranged $\kappa$ alleles could not be determined quantitatively from the data shown in Figure 1a, DN A was extracted (Quiagen Kit) from the smear region ( $>2.7 \mathrm{~kb}$; a, lane 1$)$, further digested with either BgllI (lanes 1-3) or Avall (lanes 4,5) plus methyl-sensitive restriction enzymes Sacll or $\mathrm{Hhal}$ (indicated by $\mathrm{a}+$ or - at the top), and analyzed using either probe 2 or probe 3 , as indicated. The resulting BgllI-HindIII fragment (region covered by probe 2 ) yiel ded a 0.8 - or $0.6-\mathrm{kb}$ band when the respective $\mathrm{Hhal}$ and Sacll sites are unmethylated. The Avall fragment (region covered by probe 3) was cleaved by $\mathrm{H}$ hal to yield a $0.3-\mathrm{kb}$ band if unmethylated. gested, only DN A molecules that are methylated at the Aval site will amplify. We will refer to this methyl-sensitive restriction enzyme-dependent PCR assay as MSRE-PCR.

Using MSRE-PCR, we obtained PCR products from $80 \%$ of sorted $\kappa^{+} B$ cells. To determine which alleles have been PCR amplified, we took advantage of a polymorphism between the $M$. spretus and $M$. musculus $\kappa$ genes that leads to the presence of an $\mathrm{Hhal}$ site in the $M$. musculus allele and absence of this site in the $M$. spretus allele. Whereas Hhal is itself a methyl-sensitive restriction enzyme, here it is used after PCR amplification to distinguish the two alleles. PCR products from $86 \%$ (89/ 103) of the $\kappa^{+}$B cells reveal ed only oneallele in this assay
(Table 1). Representative analyzed PCR products are shown in Figure 2b. Half the alleles are maternally ( $M$. musculus) derived and half the alleles are paternally ( $M$. spretus) derived. The small number of biallelic PCR products likely derive from instances in which the Aval enzyme has failed to cut an unmethylated allele.

We next performed a variety of control experiments to validate our results and show that this assay is efficient enough to detect both alleles in each cell. When Aval digestion is omitted, for example, only 33\% (4/12) of $\kappa^{+}$ cells yield a monoallelic PCR product (Table 1 ). These monoallelic products reflect either inefficiency in the PCR or the small fraction of $\mathrm{K}^{+} \mathrm{B}$ cells that have used $\mathrm{J} 4$ or J5 for rearrangement. An additional control involved 


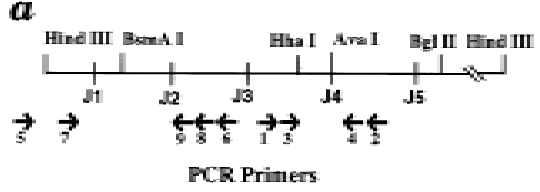

$\boldsymbol{b}$
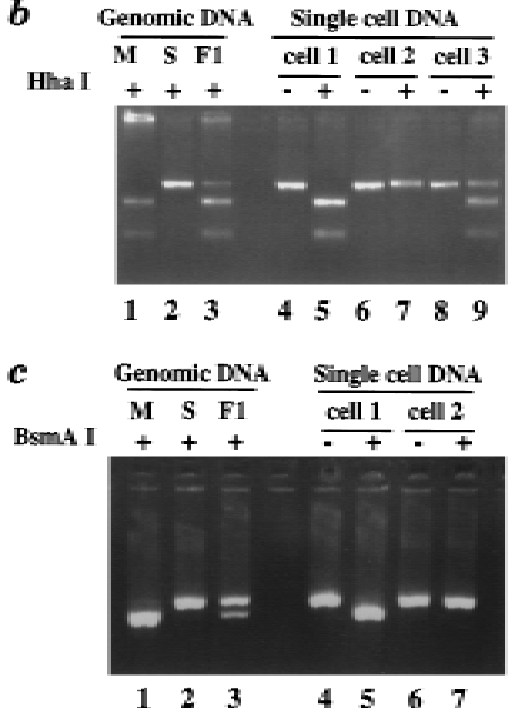

Figure 2. MSRE-PCR analysis of the $\kappa$ gene in single cells. (a) A map of the $J \kappa$ region showing the location of primers used for MSRE-PCR analysis and rel evant restriction enzyme sites. Aval was used to detect DN A methylation, whereas the polymorphic $\mathrm{Hhal}$ and BsmAI were employed to distinguish between the two $\kappa$ alleles. (b) (Lanes 1-3) As a control, genomic DN As from $M$. musculus, $M$. spretus, or $F_{1}$ mice were PCR amplified with primers $\mathrm{P} 3$ and $\mathrm{P} 4$, digested with $\mathrm{Hhal}$ (used here because of a polymorphism, not because of its methyl-sensitivity), and analyzed on a 4\% agarose gel. The $M$. musculus gene is digested, the $M$. spretus gene does not cut, and the $F_{1}$ DNA yields a product that shows $50 \%$ digestion. (Lanes 4-7) DNA from two single $\kappa^{+} B$ cells was digested with Aval and PCR amplified. (The secondary PCR primers were P1 and P2.) Uncut PCR products are in lanes 4 and 6; Hhal digested PCR products are in lanes 5 and 7. Cells 1 and 2 are monoallelic (M. musculus and $M$. spretus allele, respectively). Most $\kappa^{+} B$ cells analyzed were monoallelic. (Lanes 8, 9) The same analysis of a single midbrain cell (cell 3). Both alleles were amplified from this cell and in most of the control cells analyzed. (c) (Lanes 1-3) Control M. musculus, $M$. spretus, or $F_{1}$ genomic DN As were PCR amplified by primers $\mathrm{P} 7$ and $\mathrm{P} 9$, digested with BsmAI, and analyzed on a $4 \%$ agarose gel. (Lanes 4-7) Tertiary PCR products derived from cells 1 and 2 (from b) using primers P7 and P9. The tertiary amplification signal is dependent on the germ-line-specific primary PCR (using primers P5 and P6). Uncut PCR products are in lanes 4 and 6 , and corresponding BsmAI-digested PCR products are in lanes 5 and 7 . Cell 1 (shown previously to have a methylated $M$. musculus allele) has an unrearranged $M$. musculus allele; cell 2 (shown previously to have a methylated M. spretus allele) has an unrearranged $M$. spretus allele. All together, 15 individual cells with PCR products from both regions were analyzed.

analyzing nonlymphoid cells. When analyzed in a simiIar manner with Aval digestion preceding PCR, 85\% (33/
39) of these cells yielded biallelic PCR products; only $15 \%$ were monoallelic (Table 1 ). The $15 \%$ of products that are monoallelic probably reflect inefficiency in the $\mathrm{PCR}$, rather than undermethylation in these nonlymphoid cells. These control experiments strengthen the conclusion that one al lele is methylated and one allele is unmethylated in many individual $\kappa^{+} B$ cells.

In a second series of experiments, we expanded the MSRE-PCR single-cell assay to include a determination of which allele is rearranged. After Aval digestion, PCR primers designed to amplify only germ-line (unrearranged) DN A upstream of J3 (primers 5 and 6 ) were used in addition to the primers flanking the Aval site (primers 1 and 2) that we used in the previous experiments. In subsequent nested PCR reactions, the two regions were amplified separately. We then determined the parental origin of the resultant PCR products by digesting them with restriction enzymes whose sites are polymorphic between $M$. spretus and M. musculus. [There is a polymorphic BsmAl site in the region amplified by the primers (5 and 6) that only detect the germ-line configuration]. Figure $2 \mathrm{C}$ shows representative BsmAl digested PCR products. All 15 times we observed a PCR product for both regions, the monoallelic product reflecting methylation of the Aval site was associated with a monoallelic germ-line product from the same allele. Thus, these single-cell experiments demonstrate that the methylated allele is the germ-line allele.

\section{The kinetics of $\kappa$ chain demethylation in vivo}

We have analyzed populations of $B$ cells at various stages of B-cell development to determine the timing of $\kappa$ demethylation relative to rearrangement. The $\kappa$ locus is methylated in RAG $-1^{-1-}$ mouse $B 220^{+}$bone marrow cells (Fig. 3b, lanes 1,2), which are known to be arrested at the pro-B cell stage of differentiation (fraction $C^{\prime}$, Fig. 3a). We also examined IL-7 dependent cultured bone-marrow-derived cells (Rolink et al. 1991), which represent one of the earl iest stages in B-cell devel opment (fraction B, Fig. 3a), and observed full methylation of the $к$ locus

Table 1. Allelic methylation of the $\kappa$ gene in single cells

\begin{tabular}{|c|c|c|}
\hline \multicolumn{3}{|c|}{ Cells with monoallelic PCR product } \\
\hline +Aval) & (-Aval) & $\begin{array}{l}\text { onlymphoid cells } \\
\text { (+Aval) }\end{array}$ \\
\hline $9 / 103$ & & \\
\hline \multicolumn{3}{|c|}{$\begin{array}{l}\text { CR using primer sets P1-P4 was carried out as de- } \\
\text { laterials and M ethods with ( }+ \text { ) or without }(-) \text { pre- } \\
\text { ith A val, and the products were digested with Hhal } \\
\text { the contribution of the } \mathrm{M} \text {. spretus and M. muscu- } \\
\text { xamples shown in Fig. } 2 \mathrm{~b} \text { ). It should be noted that } \\
\text { elic products ( } 15 \% \text { ) seen in the nonlymphoid con- } \\
\text { probably due to inefficient PCR reactions. In the } \\
\text { Aval, B-cell DNA yields a high background level } \\
\text { noallelic products primarily because of rearrange- } \\
\text { or J5, which remove the primer sequences. }\end{array}$} \\
\hline
\end{tabular}


Role of $\kappa$ demethylation in B-cell development
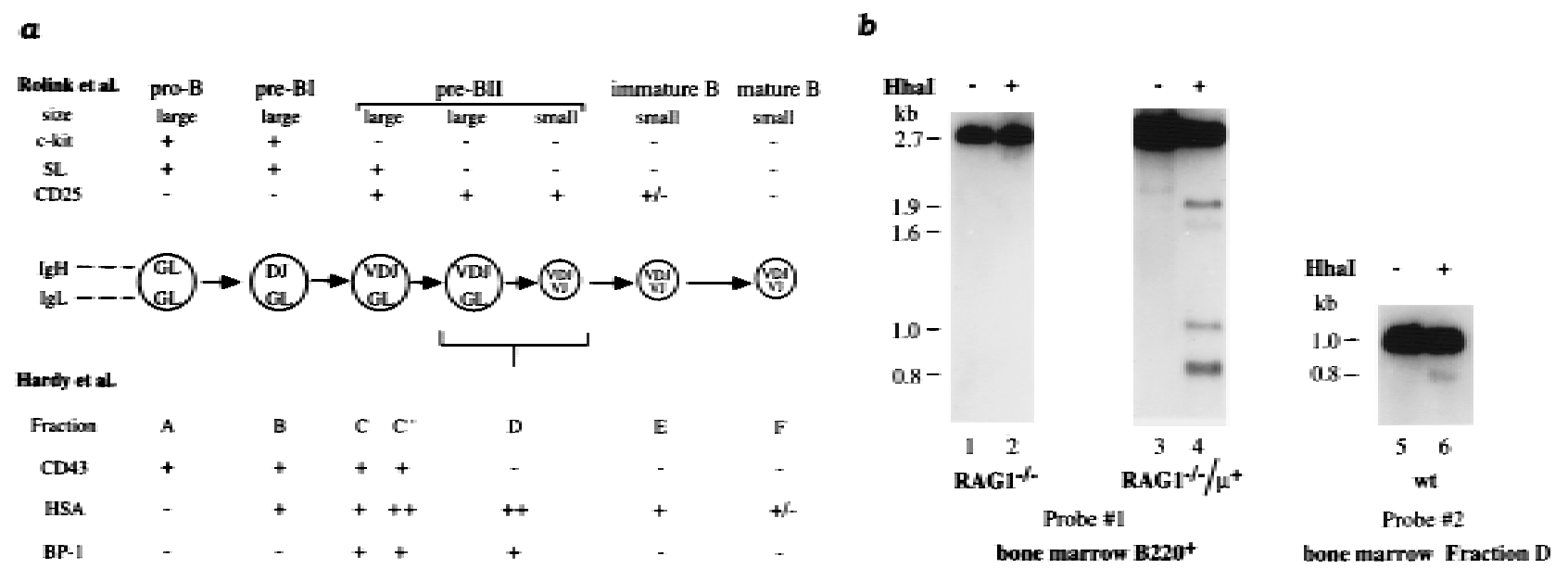

Figure 3. $\kappa$ chain demethylation in B-cell development. (a) Schematic diagram of murine B-cell devel opment (adapted from $\mathrm{N}$ utt et al. 1997). The different developmental stages of B lymphopoiesis are shown together with their characteristic cell surface markers, which are used for classification according to Rolink et al. (1994) (top) or Hardy et al. (1991) (bottom). As the correlation between the two classification systems is not straightforward in all aspects, the reader is referred to the original literature for details. (b) DN As from bone marrow B220 ${ }^{+}$cells at different stages of B-cell devel opment (see the diagram) were tested for methylation by digestion with $\mathrm{H}$ hal (+). B-cell DN A from Ragl ${ }^{-1}$ mice (arrested at the pro-B stage) (M ombaerts et al. 1992) and from Ragl ${ }^{-1-}$ mice carrying a $\mu$ transgene (arrested at the small pre-B stage) (Spanopoul ou et al. 1994) was digested by Hindlll with (+) or without (-) Hhal. DN A from wild-type (wt) fraction D cells (pre-B stage, Hardy et al. 1991; Ehlich et al. 1993) was analyzed by digestion using HindlII-BglII with (+) or without $(\rightarrow$ Hhal.

(data not shown). In contrast, analysis of bone marrow cells derived from Rag-1 ${ }^{-1-}$ mice carrying a prerearranged $\mu$ transgene (Rag- $1^{-1-} / \mu^{+}$; Spanopoul ou et al. 1994), demonstrated clear-cut $\kappa$ gene undermethylation (Fig. 3b, Ianes 3,4 ), suggesting that demethylation occurs for the first time in these pre-B cells (fraction D, Fig. 3a). This was, in fact, confirmed by the observation of $\mathrm{J}_{\kappa}$ undermethylation in normal pre-B cells isolated from bone marrow (Fig. 3b, lanes 5,6). The low level of demethylation observed is expected as fraction $D$ is made up of a mixed population containing both large and small pre-B cells and $\kappa$ rearrangement is restricted primarily to the smaller cells (ten Boekel et al. 1995). These kinetic studies demonstrate that demethylation of the $\mathrm{J} \kappa$ region occurs at about the same developmental stage in which the first $\kappa$ rearrangement events take place (Hardy et al. 1991; Ehlich et al. 1993; ten Boekel et al. 1995).

$\kappa$ chain gene allelic demethylation is independent of rearrangement

To determine whether demethylation takes place before or after rearrangement, we studied $\kappa$ gene methylation patterns in cells derived from mice in which rearrangement of the endogenous locus is prevented. In $\mathrm{i} \mathrm{E}_{\kappa} \mathrm{T}^{-1-}$ mice, where both copies of the $\kappa$ intronic enhancer are replaced by the neomycin resistance (neo) gene, rearrangement of the $\kappa$ locus is strongly inhibited and, as a result, immunoglobulin-producing cells express the $\lambda$ light chain exclusively (Takeda et al. 1993). It is likely that this dominant effect is mainly caused by the presence of the foreign neo gene, since this bacterial sequence has been shown to inhibit rearrangement even when placed at other positions in this gene (Takeda et al. 1993). We have isol ated $B 220^{+}$splenic B cells from these animals and analyzed their methylation pattern at the endogenous $\kappa$ locus. Despite the fact that both alleles remain in the germ-line configuration in these cells, $\sim 50 \%$ of the $\kappa$ gene copies undergo demethylation at $\mathrm{H}$ hal sites in the J regi on (Fig. 4a, lanes 3,4). In addition, alleles that are unmethylated at the Sacll site are also completely unmethylated at both Hhal sites (Fig. 4b, lane 3). These multiple demethylation events take place although $\sim 50 \%$ of the $\kappa$ molecules remain highly modified, indicating that in vivo demethylation mainly behaves cooperatively and occurs on one al lele at a time.

Endogenous $\kappa$ gene rearrangement is al so prevented in mice carrying a prerearranged $\kappa$ transgene (Betz et al. 1994). This effect presumably occurs because the readily synthesized transgene product constitutively turns off RAG-1 and RAG-2 expression in the B-cell lineage. We anal yzed the methylation patterns of the endogenous alleles present in these mice and found that $\sim 50 \%$ of these $\kappa$ alleles underwent demethylation (Fig. 4a, lanes 5,6).

Whereas these results indicate that demethylation can take place prior to rearrangement, we still wanted to rule out the possibility that the rearranged state itself can trigger demethylation. To this end, we examined heterozygous mice carrying a single $V_{\kappa} \mathrm{J} \kappa$ prerearranged gene (3-83кi) permanently targeted (via homologous recombination) into the normal endogenous $\kappa$ locus (Fig. 5a) (Pelanda et al. 1996). It should be noted that in these animals, the rearranged construct is actually under the control of the same endogenous cis-acting DNA elements that normally regulate $\kappa$ chain expression. As shown in figure $5 b$, the allel e that underwent homologous recom- 
a.

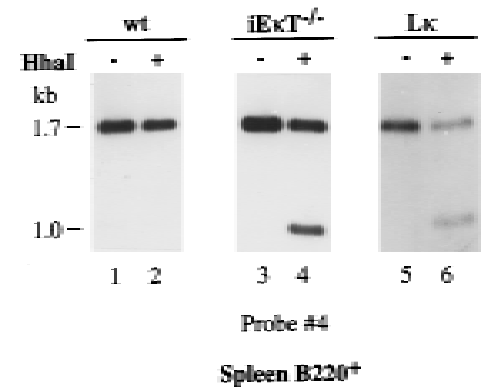

Spleen B220+ b

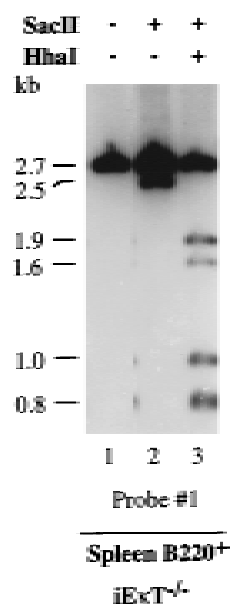

Figure 4. $\kappa$ chain demethylation and rearrangement. (a) B220 ${ }^{+}$ spleen cell DN A from wild-type (wt) mice (lanes 1,2), from mice carrying a neomycin resistance gene replacing the $\kappa$ intronic enhancer [iEk $\left.\mathrm{T}^{-1-}\right]$ (Takeda et al. 1993) (lanes 3,4), and from mice carrying a prerearranged $\kappa$-transgene [ $\mathrm{L} \kappa]$ (Sharpe et al. 1991; Betz et al. 1994) (lanes 5,6) was digested by HindlII-BgllI with $(+)$ or without $(\rightarrow)$ Hhal. Blot hybridization was performed with probe 4 (see legend to Fig. 1) to visual ize the endogenous $k$ genes exclusively. Both the endogenous $\kappa$ alleles in iEкT ${ }^{-1-}$ and Lк mice were found to be fully methylated in non-B cells (data not shown). (b) $\mathrm{B}_{22} 20^{+}$spleen cell DN A taken from iEk $\mathrm{T}^{-1-}$ mice was digested by HindlII (lane 1) with ( + ) or without ( $\rightarrow$ Sacll (lane 2) or Sacll-Hhal (lane 3) and analyzed by blot hybridization using probe 1 . N ote that al though $550 \%$ of the $\kappa$ all el es have the Sacll site unmethylated $(2.5 \mathrm{~kb})$, all of these molecules are also unmethylated at the Hhal sites, suggesting that the demethylation is of an allelic nature

bination undergoes $\sim 40 \%-60 \%$ demethylation in both bone marrow and spleen $\mathrm{B} 22 \mathrm{O}^{+}$cells, and thus appears to behave in the same manner as $\kappa$ gene copies in normal $B$ cells (Fig. 1). Furthermore, in light of the fact that many targeted molecules remain modified, it is clear that a rearranged configuration itself is not sufficient to bring about demethylation. Similar results were al so obtained in homozygous animals and in a mouse line contai ning a different prerearranged $\kappa$ allele, $V_{\kappa} 8 R$ (Luning-Prak and Weigert 1995; data not shown).

Both $\kappa$ enhancers are needed for demethylation in vivo

A recent series of mouse knockout experiments has demonstrated that both the intronic and $3^{\prime}$ enhancers play a role in $\kappa$ rearrangement, since a single deletion of either element (Gorman et al. 1996; Xu et al. 1996) partially inhi bits this process. In paral lel, we have shown by transfection experiments that both the intronic and $3^{\prime}$ enhancer sequences can individually induce $\kappa$ demethylation in B-cell lines (Lichtenstein et al. 1994; Kirillov et al. 1996). To assess the precise role of these enhancers in the demethylation process in vivo, we analyzed a se-

ries of transgenic mice carrying constructs with a prerearranged $\kappa$ light-chain gene (Sharpe et al. 1991; Betz et al. 1994). In all of these transgenes, the $\mathrm{V}_{\kappa} \mathrm{O} \times 1$ sequence is present in the rearranged configuration adjacent to $\mathrm{J}_{\kappa} 5$ which is linked to a $3^{\prime}$ region, which is either wild-type $(\mathrm{L} \kappa)$, lacking the $3^{\prime}$ enhancer $\left(\Delta 3^{\prime} \mathrm{E}_{\kappa}\right)$, or lacking the intronic enhancer ( $\Delta \mathrm{Ei}_{\kappa}$ ) (Fig. 6). To study tissue-specific demethylation, $\mathrm{B}^{2} 2 \mathrm{O}^{+}$spleen cells were isolated from these three mouse lines and the exogenous sequences then analyzed for their methylation patterns. It should be noted that transgenes in general undergo de novo methylation at the stage of implantation in the same manner as their endogenous counterparts (Frank et al. 1991). Although some B-cell-specific demethylation is

a.

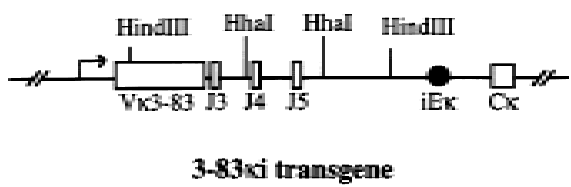

b

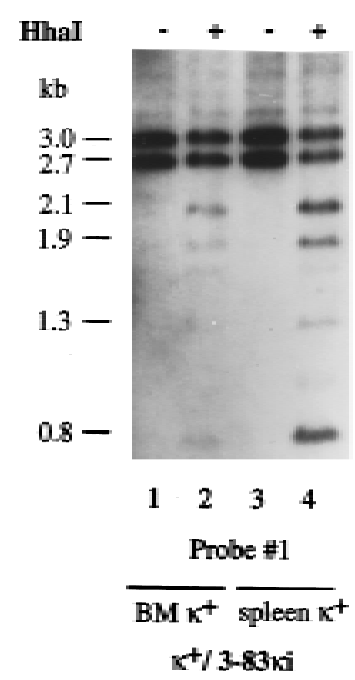

Figure 5. Demethylation in a targeted prerearranged $\kappa$ chain gene. (a) A map shows the $V_{\kappa} 3-83$ targeted gene including the intronic enhancer ( $\mathrm{i} \mathrm{E}_{\kappa}$ ) and the constant region $\left(\mathrm{C}_{\kappa}\right)$ (Pelanda et al. 1996). N ote that the rearranged construct is under the control of the same endogenous cis-acting DN A el ements that normally regulate $\kappa$ chain gene expression. (b) DN A from $\kappa^{+}$bone marrow (BM) (lanes 1,2) or spleen (lanes 3,4$)$ cells of mice carrying a rearranged $3-83 \kappa$ immunogl obulin light gene replacing one endogenous Ig allele $\left(\kappa^{+} / 3-83 \kappa i\right)$ (Pelanda et al. 1996) was digested by HindlII with $(+)$ or without $(-)$ Hhal and analyzed by blot hybridization using probe 1 . Both the wild-type germ-line copy $(2.7 \mathrm{~kb})$ and the rearranged al lele $(3.0 \mathrm{~kb})$ can be seen on the gel. The $\mathrm{H}$ hal digestion products include the $2.1-\mathrm{kb}$ band that is derived exclusively from the rearranged allele and the $0.8-\mathrm{kb}$ band that comes from both alleles. Similar results were obtained with DNA from homozygous 3-83кi mice (data not shown). 

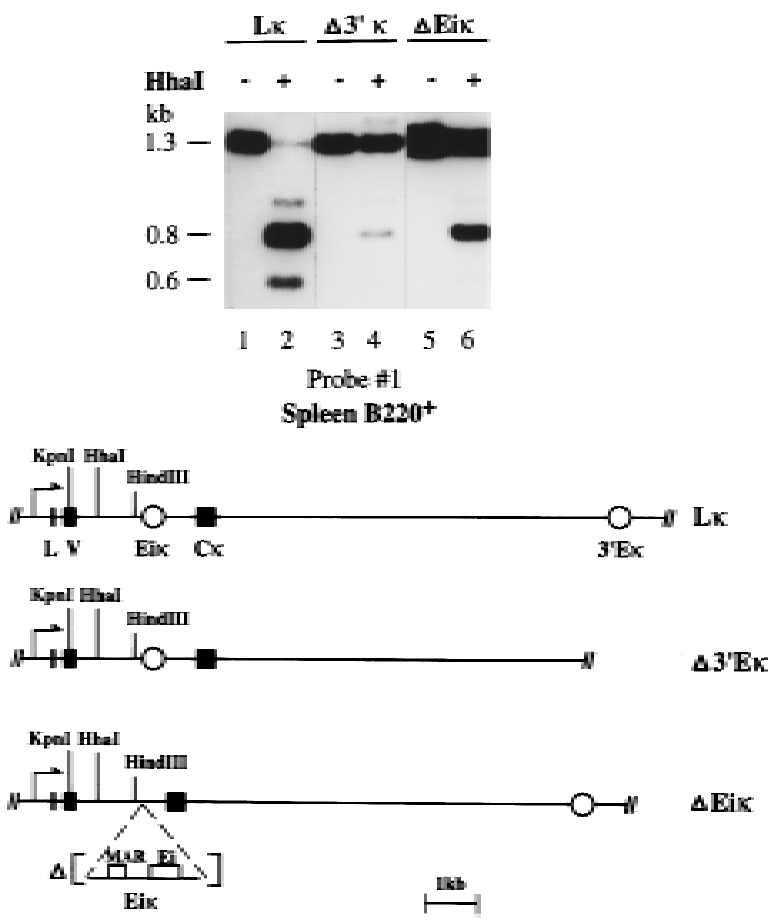

Figure 6. Enhancers required for $\kappa$ gene demethylation in vivo. $\mathrm{B}_{22} \mathrm{C}^{+}$spleen cell ( $>95 \%$ purity by FACS analysis) DNA from mice carrying a complete $V_{\kappa} J_{\kappa}$ rearranged transgene [ $\mathrm{L} \kappa_{\kappa}$ ] (lanes $1,2)$ or constructs individually lacking either the $3^{\prime}$ enhancer $\left[\Delta 3^{\prime} \mathrm{EK}_{\kappa}\right]($ lanes 3,4$)$ or the intronic enhancer $\left[\Delta \mathrm{Ei}_{\kappa}\right]($ lanes 5,6$)$ (Betz et al. 1994) was digested by HindlII-Kpnl with (+) or without $(-)$ Hhal. The 1.3-kb HindllI-Kpnl fragment and its 0.6-kb unmethylated digestion product are derived exclusively from the exogenous transgene; the $0.8-\mathrm{kb}$ band is a common product of both the endogenous and transgenic copies. The accompanying map shows the various transgenes used in this experiment (Betz et al. 1994).

observed when either the intronic or $3^{\prime} \mathrm{k}$ enhancer is present alone (Fig. 6, lanes 3-6), full demethylation was only obtained in the wild-type construct, where both enhancers are present on the same molecule (Fig. 6, lanes $1,2)$. Thus, al though either the intronic or $3^{\prime} k$ enhancer is sufficient to induce demethylation in B-cell cultures (Kirillov et al. 1996), both enhancers are required for optimal demethylation in vivo. These experiments demonstrate that both demethylation and rearrangement are controlled by the same combination of genetic el ements.

\section{Discussion}

In B cells functional rearrangement at a given immunoglobulin locus occurs on only one of two identical alleles, a phenomenon termed al lelic exclusion. Inefficiency in the rearrangement process itself has been suggested as a potential mechanism underlying this selection (Coleclough et al. 1981). Inefficiency would then require a feedback mechanism to shut off further rearrangement when a functional receptor has been made. Otherwise, even an inefficient process would eventually result in rearrangement on the second allele. The well-documented existence of feedback down-regulation of the $V(D)$ J recombinase maintains the viability of the inefficiency model explaining the establishment of al lelic exclusion (Rajewsky 1996). However, another possibility is that when the trans-acting factors establish a cellular environment conducive to rearrangement of a gi ven family, only one of the two alleles is available initially for rearrangement. Indeed, the experiments we present here lead us to suggest that the establ i shment of $\kappa$ gene all lel ic exclusion involves a demethylation event that marks one of the two $\mathrm{k}$ alleles for subsequent rearrangement.

\section{$\kappa$ demethylation is monoallelic}

We have performed two distinct experiments, each of which on its own demonstrates that in normal $\kappa^{+} B$ cells, $\kappa$ demethylation is monoallelic. One analysis involved examining DNA prepared from populations of purified $\kappa^{+} B$ cells using methyl-sensitive restriction enzymes and Southern blotting. We also developed a novel assay that allowed us to analyze the methylation status of the two $\kappa$ al leles in individual $\kappa^{+} B$ cells. These experiments demonstrate that $\kappa^{+} B$ cells contain a rearranged, unmethylated al lel e coexisting with a germ-line al lele that is methylated, and, to our knowledge, are the first to analyze the methylation status of the two $\kappa$ alleles in individual cells in vivo. Previous studies using B lineage cell lines had suggested that germ-line alleles are undermethylated to the same extent as rearranged copies (M ather and Perry 1983; Storb and Arp 1983). However, in light of our in vivo results, it is likely that the generally unmethylated pattern they observed is caused by a cell culture or transformation artifact.

\section{Demethylation precedes rearrangement}

By analyzing B cells isolated from bone marrow of both normal and mutant mice, we determined that $\kappa$ demethylation in vivo takes place at the pre-B cell transition stage (see Fig. 3a,b). It was not clear from these studies, however, whether the $\kappa$ gene undergoes demethylation before or after the rearrangement event. We have used a genetic approach to distinguish between these two possibilities. We examined mice in which the rearrangement of the $\kappa$ alleles is inhibited in cis (Takeda et al. 1993), and mice in which $\kappa$ rearrangement is prevented by a trans-acting mechanism (Betz et al. 1994). In both cases, roughly half of the endogenous (germ-line) alleles undergo demethylation in $\kappa^{+}$lymphocytes, a pattern clearly reminiscent of the allele-specific demethylation observed in normal B cells. These results thus indicate that rearrangement is not necessary for the $\kappa$ allele to undergo demethylation. We have al so been able to prove that rearrangement is not sufficient to bring about demethylation. Indeed, our studies show that a prerearranged $\kappa$ gene inserted into the normal $\kappa$ locus (Pelanda et al. 1996) only undergoes partial demethylation in B cells. Taken together, these results strongly suggest that 
during normal B-cell development demethylation immediately precedes rearrangement.

\section{Demethylation is necessary for rearrangement}

The strong correlation between undermethylation and rearrangement raises the possibility that DNA methylation itself may inhibit the rearrangement process; several published experiments support this model. Using a simple transfection system, for example, it has been shown that plasmids containing the minimal heptamer/ nonamer signal sequences readily undergo rearrangement in B cells. However, when these templates are first methylated in vitro and then allowed to undergo replication in the transfected cells, rearrangement is severely inhibited (Hsieh and Lieber 1992). M ore convincing evidence that methylation represses rearrangement was obtained by examining mice carrying a transgene construct containing basic rearrangement signals. In a C57BL/ 6 background, this transgene is apparently methylated in every tissue. However, when bred into the DBA/2 strain, this same transgene remains unmethylated throughout the organism and only in this unmethylated state does B-cell-specific rearrangement take place (Engler et al. 1991). It should be noted that in this experiment, the methylation pattern is control led by modifier genes that have nothing to do with the signals normally used in B cells, and for this reason it provides convincing evidence that local DNA methylation itself plays a critical role in inhibiting gene rearrangement.

By empl oying transgenes containing a prerearranged $\kappa$ gene configuration (Betz et al. 1994), it was possible to evaluate the effect of the intronic and $3^{\prime} \kappa$ enhancers on demethylation in vivo independent of the rearrangement process. Our results indicate that although each enhancer alone can induce a small amount of B-cell-specific demethylation, full demethylation of the $\kappa$ locus is only seen when both are present together in cis. Recent mouse knockout experiments have demonstrated that single deletions of either the intronic or $3^{\prime}$ enhancer are sufficient to partially inhibit $\kappa$ gene rearrangement ( $T$ akeda et al. 1993; Gorman et al. 1996; Xu et al. 1996). It thus appears that in vivo the same genetic elements are involved in both demethylation and rearrangement. One attractive explanation for these results is that the enhancers work by inducing demethylation which, in turn, allows rearrangement at the same locus.

It is interesting to consi der data suggesting a role for methylation in regulating rearrangement at the heavychain gene locus in the mouse. The $\mu$ enhancer together with its accompanying MAR sequences have been shown to induce demethylation on transfected constructs in B-cell cultures and in vivo (Fernex et al. 1995; Kirillov et al. 1996). Furthermore, when this element is deleted from its normal locus in vivo, heavy-chain rearrangement is inhibited (Chen et al . 1993; Serwe and Sablitzky 1993). Because unmethylated constructs lacking either the heavy- or light-chain enhancer elements readily undergo rearrangement following transfection into pre-B cells in culture (Hesse et al. 1987; Lieber et al.
1987), it is clear that these cis-acting sequences are not required for carrying out the mechanical aspects of recombination. It is likely that in vivo the absence of the $\mu$ enhancer prevents this site from undergoing stage-specific demethylation, and it is for this reason that rearrangement is repressed. In a similar manner, DN A methylation may also play a role in the control of rearrangement at the T-cell-receptor locus (Oyashiki et al. 1992; Capone et al. 1993; Okada et al. 1994; Bories et al. 1996).

\section{Role of demethylation in rearrangement and allelic} exclusion

On the basis of our results it is now possible to understand how DN A methylation may play a role in regulating $\kappa$ gene rearrangement. In pro-B cells, at a stage when the heavy-chain locus undergoes multiple rearrangement events, the $\kappa$ alleles are still fully methylated, and it is probably this methylation, in the context of chromatin structure, which prevents their rearrangement despite the presence of RAG-1 and RAG-2 activity in these cells (Grawunder et al. 1995). The expression of a productive $\mu$ chain appears to bring about a number of dramatic changes in the $\kappa$ locus, including the initiation of $\kappa$ germ-line transcription (Spanopoulou et al. 1994), an increase in chromatin accessibility (Stanhope-Baker et al. 1996), and monoallelic demethylation of the sequences adjacent to the $\mathrm{J} \kappa$ region (Fig. $3 \mathrm{~b}$ ). All of these events probably occur prior to rearrangement, and it is likely that they are mediated through trans-acting factors that are triggered by the presence of a functional $\mu$ chain. NF-кB, for example, is al ready bound to the $\kappa$ intronic enhancer at this stage (Shaffer et al . 1997), and has been demonstrated to be required for $\kappa$ demethylation in a transfection system (Demengeot et al. 1995; Kirillov et al. 1996).

Our results clearly suggest that $\kappa$ gene demethylation takes place preferentially on only one allele in each cell, and it is probably this demethylation that selects the gene copy that will ultimately undergo rearrangement. The synthesis of a functional $\kappa$ chain completes the generation of the B-cell receptor and thus down-regulates the expression of RAG-1 and RAG-2. This down-regulation probably serves as a backup mechanism for preventing further rearrangement. In the absence of a productive $\kappa$ chain it is possible that, given enough time, the second allele in the same cell will eventually undergo demethylation and subsequent rearrangement. This is consistent with our finding (Fig. 1) that all rearranged al leles in $B$ cells are unmethylated.

A number of previous observations also support the idea that differences between the two al leles render one available for rearrangement prior to the other. For example, in IgM ${ }^{+}$immature $B$ cells, double-stranded DN A breaks were detected at the $\mathrm{J} \kappa 2$ and $\mathrm{J} \kappa 5$ signal sequences, but not at the initially preferred Jk1 site, strongly suggesting that one allele can undergo repeated rearrangement events, whereas the other $\kappa$ copy in the same cell is maintained in the germ-line configuration (Constantinescu and Schlissel 1997). These results are consistent 
with the observation that in cells carrying a prerearranged autoreactive $\kappa$ gene, secondary rearrangements that introduce al ternate variable regi ons take place preferentially on this same allele (Chen et al. 1997). This editing procedure presumably serves as a molecular mechanism for rescuing cells from deletion or anergy. It thus appears that complex regulation of $\kappa$ gene rearrangement timing and allel e selection is most likely mediated through changes in accessibility, and our data clearly indicate that demethylation plays an important role in this process. Yet another line of support comes from single-cell analysis of B cells carrying a prerearranged knock-in $\left(\mathrm{V}_{\kappa} 8 \mathrm{R}\right.$ or $\mathrm{V}_{\kappa} 4 \mathrm{R}$ ) on one allele (Luning-Prak and Weigert 1995). Our calculations show that in $>90 \%$ of these cells, either the targeted or the natural allele, but not both, undergo rearrangement events. This suggests that there is indeed a mechanism for sel ecting one allele at a time which is independent of whether or not a productive $\kappa$ gene can be synthesized. If such a primary mechanism did not exist, the rearranged construct should have brought about complete closure of the second allele in every cell.

There are several ways to explain how demethylation might initially occur on a single allele in each developing $B$ cell. One possibility is that the demethylation enzyme machinery is present in limiting amounts in the cell and only suffices to remove methyl moieties from one allele at a time. In this model, demethylation itself would represent the rate-limiting step for al lel e selection. A Iternatively, one $\kappa$ allele in each B cell may already carry a preset cis-acting molecular marker that serves to direct the demethylation process. Although there is no direct evidence for either mechanism, our data show that a multi copy prerearranged $\kappa$ transgene, integrated at an ectopic site in the genome, can undergo full demethylation in B cells, clearly suggesting that the demethylation potential is not rate limiting. In contrast to the $\kappa$ transgene, a prerearranged construct knocked in to the endogenous $\kappa$ locus itself became only partially unmethylated, probably because it is subject to cis-acting restrictions normally dictated by this gene region. In light of these data, we favor the hypothesis that the two alleles are differentially marked well before the initiation of $\kappa$ gene rearrangement.

It thus appears that the process of allele selection at the $\kappa$ locus may actual ly be analogous to the mechanism that controls olfactory receptor gene expression. In this case, as well, although the choice of receptor gene activation in any given olfactory neuron is carried out stochastically, chromosome structure limits this process to only a single allele (Chess et al. 1994). Thus, for both the immunoglobulin and ol factory receptor loci, structural allelic exclusion appears to be a primary mechanism for insuring the production of a single gene product from a large array.

\section{Materials and methods}

Animals

Wild-type $\mathrm{C} 57 \mathrm{BL} / 6 \times \mathrm{BALB} / \mathrm{c} \mathrm{F}_{1}$ mice were obtained from our own colony. iEk $\mathrm{T}^{-1-}$ and 3-83кi mice were obtained from S. Takeda (Kyoto University, Japan) and K. Rajewsky (University of Cologne, Germany). $V_{\kappa} 8 R$ mice were obtained from $M$. Weigert, and $L_{\kappa}, \Delta 3^{\prime} E_{\kappa}$ and $\Delta \mathrm{Ei}_{\kappa}$ mice from $\mathrm{M}$. Neuberger (MRC, Cambridge, UK). All mice were analyzed the age of 8-12 weeks.

Immunofluorescence staining, cell sorting, purification, and analysis

Cell suspensions from bone marrow were prepared by flushing six to eight femura with PBS and then washing by centrifugation through PBS. Spleen cells were prepared by disruption in PBS, followed by gentle pi petting, and centrifuging through PBS.

$M$ ouse spleen or bone marrow $B$ cells were enriched by means of staining with either a biotinylated anti-к or anti-B220 antibody (PharMingen), followed by incubation with streptavidincoated magnetic beads (Miltenyi Biotec). Cells were sorted by magnetic cell sorting using the MACS system (Miltenyi et al. 1990). Cells bound to the column in the magnetic field were eluted and recovered for subsequent DNA analysis. Purity (> $90 \%$ ) was assessed by flow cytometry (FACS) analysis after restaining with streptavidin-conjugated phycoerythrin (Jackson Laboratory). Wild-type fraction D cells were prepared by a dual laser-dye flow cytometer (FACStar, Becton-Dickinson). Cells were stained with anti-B220-PE, anti-CD43-FITC, and anti-IgM -

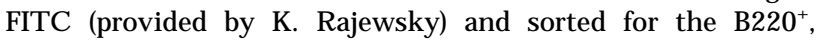
$\mathrm{CD}^{-} 3^{-}, \mathrm{IgM}^{-}$fraction (97\% purity). Sorted cells were washed once with PBS and stored for subsequent DN A analysis. CelluIar DN A (4-8 $\mu \mathrm{g})$ was digested, el ectrophoresed in native (Trisacetate) agarose gels, and transferred to nitrocellulose. DNA was then hybridized with the specific radioactive probes (see Fig. 1) and analyzed by autoradiography (Southern 1975). Hybridization was carried out at $65^{\circ} \mathrm{C}$ for $16 \mathrm{hr}$. In some cases, the degree of undermethylation was measured semiquantitavely using a Phosphorlmager.

\section{MSRE-PCR analysis on single cells}

We modified the single-cell PCR method of Bertram et al . (1995) to include a MSRE analysis. Briefly, spleen cells from an $F_{1}$ progeny of a cross between $M$. spretus and $M$. musculus were stained with a rat anti-mouse $\kappa$ light chain monoclonal antibody (R5-240, PharMingen, FITC conjugated). Individual $\mathrm{\kappa}^{+}$ cells were FACS sorted directly into $25 \mu$ of Iysis buffer $(50 \mathrm{~mm}$ $\mathrm{KCl}, 2.5 \mathrm{~mm} \mathrm{M} \mathrm{gCl}_{2}, 0.5 \%$ Tween 20, 0.5\% N P-40, 10 mm Tris$\mathrm{HCl}$ at $\mathrm{pH}$ 8.3) in individual PCR tubes. The genomic DNA was liberated using proteinase $\mathrm{K}\left(0.001 \mathrm{mg} / \mathrm{ml}\right.$ at $60^{\circ} \mathrm{C}$ for $\left.2 \mathrm{hr}\right)$, that was then inactivated with PMSF $\left(0.002 \mathrm{mg} / \mathrm{ml}, 60^{\circ} \mathrm{C}\right.$, for $\left.1 \mathrm{hr}\right)$. The genomic DN A was subjected to digestion overnight at $37^{\circ} \mathrm{C}$ with 20 units of Aval.

PCR was performed with Taq DNA polymerase (Promega) under standard conditions $(50 \mathrm{mM} \mathrm{KCl}, 0.1 \%$ Triton X-100, 1.5 $\mathrm{mm} \mathrm{MgCl}_{2}, 10 \mathrm{~mm}$ Tris- $\mathrm{HCl}$ at $\mathrm{pH} 8.3,200 \mu \mathrm{m}$ each of all four dNTPs, 50 ng each of primer). The first-round PCR reaction was carried out in $50 \mu \mathrm{l}$ using primers P1 (5'-TGAAGTTTTGGTCCCATTGTGTCC-3') and P2 (5'-CCTAAGACGAGTTTTTCGCTCAGCTTTC- $3^{\prime}$ ), which flank the Aval site. Amplification was performed as follows: $4 \mathrm{~min}$ at $94^{\circ} \mathrm{C} ; 40$ cycles of $1 \mathrm{~min}$ at $94^{\circ} \mathrm{C}, 1 \mathrm{~min}$ at $55^{\circ} \mathrm{C}$, and $1 \mathrm{~min}$ at $72^{\circ} \mathrm{C}$; and, finally, $4 \mathrm{~min}$ at $72^{\circ} \mathrm{C}$. Second-round PCR conditions were identical to the first round except that $2 \mu$ of the first-round amplification product was added to the PCR mixture containing primers P3 (5'GTGGGAGAAATGAGAAAGGAACAG-3') and P4 (5'-TGGGGGATCTTCTATTGATGCAC-3'). The second-round PCR 
product was subjected to digestion with $\mathrm{H}$ hal and analyzed by agarose gel electrophoresis.

MSRE-multiplex PCR on single cells was performed to simultaneously amplify the unrearranged $\kappa$ DNA in addition to the region flanking the Aval site (described above). The following primers were used simultaneously: P1, P2, P5 (5'-AGATCCTATGGAAGAGCAGCGAG-3'), and P6 (5'-TTTACCTCCACAAAACCCTCCCC-3'). 50 cycles of amplification were performed using the conditions of the first-round PCR described above. In the second-round PCR, the two distinct regions were amplified in separate tubes in reactions whose conditions were identical (except that each time segment was $45 \mathrm{sec}$ ) to the previously described second-round. The following primers (nested within the first-round primers) were used: P7 (5'-CGGGATCCCGGTGGAGGCACCAAGCTG-3') and P8 (5'-GCTCTAGACCTCCACAAAACCCTCCCTAGG-3'). To visualize products from a larger fraction of cells, a third round (40 cycle) PCR was carried out using primers P7 and P9 (5'-CTGATCTGAGAATGGAATTTGCTAAATCCCTG-3'). This third-round PCR product was subjected to digestion by the restriction enzyme BsmAI and analyzed by agarose gel electrophoresis.

\section{Acknowledgments}

We thank K. Rajewsky, S. Takeda, M. Wiegert, and M. N euberger for providing the trangenic mice used in this study; S. Jung, $\mathrm{T}$. Wirth, and S. Schaal for their collaboration and for providing antibodies; G. N eiman from the Interdepartmental Equipment Unit at the Hebrew University Medical School for technical assistance with the FACS sorting; and G. Paradis of the MIT flow cytometry core facility. We also acknowledge the assistance of G. Hirst in preparing the manuscript. This research was supported by grants from the Israel Science Foundation (Y.B. and H.C.), the German-Israeli Foundation for Scientific Research and Development (Y.B.), the $\mathrm{N}$ ational Institutes of Health (H.C. and A.C.), the Israel Cancer Research Fund (H.C.), the Israel Science M inistry (H.C.), and the Ira W. DeCamp Foundation created under the will of Elizabeth DeCamp-Mclnery (A.C.). A.C. is a Rita Allen Foundation Scholar and R.M. is the recipient of a fellowship from the Israel Ministry of Science and the Arts.

The publication costs of this article were defrayed in part by payment of page charges. This article must therefore be hereby marked "advertisement" in accordance with 18 USC section 1734 solely to indicate this fact.

\section{References}

Bertram, S., F.T. Hufert, D.N. Haefelin, and D. von Laer. 1995. Detection of DNA in single cells using an automated cell deposition unit and PCR. BioTechniques 19: 616-620.

Betz, A.G., C. Milstein, A. Gonzalez-Fernandez, R. Pannel, T. Larson, and M.S. N euberger. 1994. Elements regulating somatic hypermutation of an immunogl obulin $\kappa$ gene: Critical role for the intron enhancer/matrix attachment region. Cell 77: 239-248.

Bories, J.-C., J. Demengeot, L. Davidson, and F.W. Alt. 1996. Gene-targeted deletion and replacement mutations of the $T$-cell receptor $\beta$-chain enhancer: The role of enhancer elements in controlling $\mathrm{V}(\mathrm{D})$ ) recombination accessibility. Proc. Natl. Acad. Sci. 93: 7871-7876.

Capone, M., F. Watrin, C. Fernex, B. Horvat, B. Krippl, L. Wu, R. Scollay, and P. Ferrier. 1993. TCR $\beta$ and TCR $\alpha$ gene enhancers confer tissue- and stage-specificity on $\mathrm{V}(\mathrm{D}) \mathrm{J}$ recombination events. EMBO J. 12: 4335-4346.
Chen, C., E. Luning Prak, and M. Weigert. 1997. Editing diseaseassociated autoantibodies. Immunity 6: 97-105.

Chen, J., F. Y oung, A. Bottaro, V. Stewart, R.K. Smith, and F.W. Alt. 1993. Mutations of the intronic IgH enhancer and its flanking sequences differentially affect accessibility of the JH locus. EMBO J. 12: 4635-4645.

Chess, A., I. Simon, H. Cedar, and R. Axel. 1994. Allelic inactivation regulates olfactory receptor gene expression. Cell 78: 823-834.

Coleclough, C., R.P. Perry, K. Karjalainen, and M. Weigert. 1981. A berrant rearrangements contribute significantly to the allelic exclusion of immunoglobulin gene expression. Nature 290: 372-378.

Constantinescu, A. and M. Schlissel. 1997. Changes in locusspecific $V(D)$ ] recombinase activity induced by immunogl obulin gene products during B cell development. J. Exp. Med. 185: 609-620.

Demengeot, J., E.M. Oltz, and F.W. Alt. 1995. Promotion of $\mathrm{V}(\mathrm{D})$ ] recombinational accessibility by the intronic $E_{\kappa}$ element: Role of the $\kappa$ B motif. Int. Immunol. 7: 1995-2003.

Ehlich, A., S. Schaal, H. Gu, D. Kitamura, W. Muller, and K. Rajewsky. 1993. Immunoglobulin heavy and light chain genes rearrange independently at early stages of B cell development. Cell 72: 695-704.

Engler, P., D. Haasch, C.A. Pinkert, L. Doglio, M. Glymour, R. Brinster, and U. Storb. 1991. A strain-specific modifier on mouse chromosome 4 controls the methylation of independent transgene loci. Cell 65: 1-20.

Fernex, C., M. Capone, and P. Ferrier. 1995. The V(D)J recombinational and transcriptional activities of the immunoglobulin heavy-chain intronic enhancer can be mediated through distinct protein-binding sites in a transgenic substrate. Mol. Cell. Biol. 15: 3217-3226.

Forrester, W.C., C. van-Genderen, T. Jenuwein, and R. Grosschedl. 1994. Dependence of enhancer-mediated transcription of the immunoglobulin $\mu$ gene on nuclear matrix attachment regions. Science 265: 1221-1225.

Frank, D., I. Keshet, M. Shani, A. Levin, A. Razin, and H. Cedar. 1991. Demethylation of C pG islands in embryonic cells. Nature 351: 239-241.

Gellert, M. 1996. A new view of $V(D) J$ recombination. Genes Cells 1: 269-275.

Goodhardt, M., P. Cavelier, N. Doyen, S. Kallenbach, C. Babinet, and F. Rougeon. 1993. Methylation status of immunoglobulin $\kappa$ gene segments correlates with their recombination potential. Eur. J. Immunol. 23: 1789-1795.

Gorman, J.R., N. van-der-Stoep, R. Monroe, M. Cogne, L. Davidson, and F.W. Alt. 1996. The lgk 3' enhancer influences the ratio of Igk versus Ig $B$ Iymphocytes. Immunity 5: 241-252.

Grawunder, U., T.M. Leu, D.G. Schatz, A. Werner, A.G. Rolink, F. Melchers, and T.H. Winkler. 1995. Down-regulation of RAG1 and RAG2 gene expression in pre-B cells after functional immunoglobulin heavy chain rearrangement. Immunity 3: 601-608.

Hardy, R.R., C.E. Carmack, S.A. Shinton, J.D. Kemp, and K. Hayakawa. 1991. Resolution and characterization of pro-B and pre-pro-B cell stages in normal mouse bone marrow. J. Exp. Med. 173: 1213-1225.

Hesse, J.E., M.R. Lieber, M. Gellert, and K. Mizuuchi. 1987. Extrachromosomal DNA substrates in pre-B cells undergo inversion or deletion at immunoglobulin V-(D)-J joining signals. Cell 49: 775-783.

Hsieh, C.L. and M.R. Lieber. 1992. CpG methylated minichromosomes become inaccesible for $\mathrm{V}(\mathrm{D}) \mathrm{J}$ recombination after undergoing replication. EMBO J. 11: 315-325.

Jenuwein, T., W.C. Forrester, R.G. Qiu, and R. Grosschedl. 
1993. The immunogl obulin $\mu$ enhancer core establishes local factor access in nuclear chromatin independent of transcriptional stimulation. Genes \& Dev. 7: 2016-2032.

Kelley, D.E., B.A. Pollok, M.L. Atchison, and R.P. Perry. 1988. The coupling between enhancer activity and hypomethylation of $\kappa$ immunoglobulin genes is developmentally regulated. Mol. Cell. Biol. 8: 930-937.

Kirillov, A., B. Kistler, R. M ostoslavsky, H. Cedar, T. Wirth, and Y. Bergman. 1996. A role for nuclear N F-кB in B-cell-specific demethylation of the Igk locus. Nature Genet. 13: 435-441.

Lewis, S.M. 1994. The mechanism of $V(D)$ J joining: Lessons from molecular, immunological, and comparative analyses. Adv. Immunol. 56: 27-150.

Lichtenstein, M., G. Keini, H. Cedar, and Y. Bergman. 1994. B cell-specific demethylation: A novel role for the intronic $\mathrm{k}$ chain enhancer sequence. Cell 76: 913-923.

Lieber, M.R., J.E. Hesse, K. Mizuuchi, and M. Gellert. 1987. Developmental stage specificity of the lymphoid $V(D) J$ recombination activity. Genes \& Dev. 1: 751-761.

Luning-Prak, E. and M. Weigert. 1995. Light chain replacement: A new model for antibody gene rearrangement. J. Exp. Med. 182: 541-548.

M ather, E.L. and R.P. Perry. 1983. M ethylation status and DN ase I sensitivity of immunoglobulin genes: Changes associated with rearrangement. Proc. Natl. Acad. Sci. 80: 46894693.

Miltenyi, S., W. Muller, W. Weichel, and A. Radbruch. 1990. High gradient magnetic cell separation with MACS. Cytometry 11: 231-238.

Mombaerts, P., J. Iacomini, R.S. Johnson, K. Herrup, S. Tonegawa, and V.E. Papai oannou. 1992. RAG-1-deficient mice have no mature $B$ and $T$ Iymphocytes. Cell 68: 869-877.

Mostoslavsky, R. and Y. Bergman. 1997. DNA methylation: Regulation of gene expression and role in the immune system. Biochim. Biophys. Acta 1333: F29-F50.

N utt, S.L., P. Urbanek, A. Rolink, and M. Busslinger. 1997. Essential functions of Pax5 (BSAP) in pro-B cell development: Difference between fetal and adult $B$ Iymphopoiesis and re duced V-to-DJ recombination at the IgH locus. Genes \& Dev. 11: 476-491.

Oettinger, M .A., D.G. Schatz, C. Gorka, and D. Baltimore. 1990. RAG-1 and RAG-2, adjacent genes that synergistically activate $V(D)$ J recombination. Science 248: 1517-1523.

Ohyashiki, J.H., K. Ohyashiki, K. Kawakubo, T. Tauchi, S. Nakazawa, N. Kimura, and K. Toyama. 1992. T-cell receptor $\beta$ chain gene rearrangement in acute myel oid leukemia al ways occurs at the allele that contains the undermethylated $J \beta 1$ region. Cancer Res. 52: 6598-6602.

Okada, A., M. Mendelsohn, and F. Alt. 1994. Differential activation of transcription versus recombination of transgenic $T$ cell receptor $\beta$ variable region gene segments in $B$ and $T$ lineage cells. J. Exp. Med. 180: 261-272.

Pelanda, R., S. Schaal, R.M. Torres, and K. Rajewsky. 1996. A prematurely expressed Igk transgene, but not a $V_{\kappa} J_{\kappa}$ gene segment targeted into the Igk locus, can rescue $B$ cell development in $\lambda$ 5-deficient mice. Immunity 5: 229-239.

Rajewsky, K. 1996. Clonal selection and learning in the antibody system. Nature 381: 751-758.

Rolink, A., A. Kudo, H. Karasuyama, Y. Kikuchi, and F. M el chers. 1991. Long-term proliferating early pre-B cell lines and clones with the potential to develop to surface Ig-positive, mitogen reactive $B$ cells in vitro and in vivo. EMBO J. 10: 327-336

Rolink, A., U. Grawunder, T.H. Winkler, H. Karasuyama, and F. M elchers. 1994. IL-2 receptor $\alpha$ chain (CD25, TAC) expression defines a crucial stage in pre-B cell development. Int.
Immunol. 6: 1257-1264

Schatz, D.G., M .A. Oettinger, and D. Baltimore. 1989. The V(D)J recombination activating gene, RAG-1. Cell 59: 1035-1048.

Serwe, M. and F. Sablitzky. 1993. V(D)] recombination in B cells is impaired but not blocked by targetted deletion of the immunoglobulin heavy chain intron enhancer. EMBO J. 6: 2321-2327.

Shaffer, A.L., A. Peng, and M.S. Schlissel. 1997. In vivo occupancy of the $\kappa$ light chain enhancers in primary Pro- and Pre-B cells: A model for $\kappa$ locus activation. Immunity 6: 131143.

Sharpe, M.J., C. Milstein, J.M. Jarvis, and M.S. N euberger. 1991. Somatic hypermutation of immunoglobulin kappa may depend on sequences $3^{\prime}$ of $C \kappa$ and occurs on passenger transgenes. EMBO J. 10: 2139-2145.

Southern, E.M. 1975. Detection of specific sequences among DNA fragments separated by gel electrophoresis. J. Mol. Biol. 98: 503-517.

Spanopoulou, E., C.A. Roman, L.M. Corcoran, M.S. Schlissel, D.P. Silver, D. N emazee, M.C. N ussenzweig, S.A. Shinton, R.R. Hardy, and D. Baltimore. 1994. Functional immunoglobulin transgenes guide ordered B-cell differentiaton in Rag-1-deficient mice. Genes \& Dev. 8: 1030-1042.

Stanhope-Baker, P., K.M. Hudson, A.L. Shaffer, A. Constantinescu, and M. Schlissel. 1996. Cell type-specific chromatin structure determines the targeting of $\mathrm{V}(\mathrm{D}) \mathrm{J}$ recombinase activity in vitro. Cell 85: 887-897.

Storb, U. and B. Arp. 1983. Methylation patterns of immunoglobulin genes in lymphoid cells: Correlation of expression and differentiation with undermethylation. Proc. Natl. Acad. Sci. 80: 6642-6646.

Takeda, S., Y.-R. Zou, H. Bluethmann, D. Kitamura, U. Muller, and K. Rajewsky. 1993. Deletion of the immunoglobulin $\kappa$ chain intron enhancer abolishes $\kappa$ chain gene rearrangement in cis but not $\lambda$ chain gene rearrangement in trans. EMBO J. 12: 2329-2336.

ten Boekel, E., F. M elchers, and A. Rolink. 1995. The status of Ig loci rearrangements in single cells from different stages of B cell development. Int. Immunol. 7: 1013-1019.

Xu, Y., L. Davidson, F.W. Alt, and D. Baltimore. 1996. Deletion of the Igk light chain intronic enhancer/matrix attachment region impairs but does not abolish $\mathrm{V}_{\kappa} \mathrm{J}_{\kappa}$ rearrangement. Immunity 4: 377-385. 


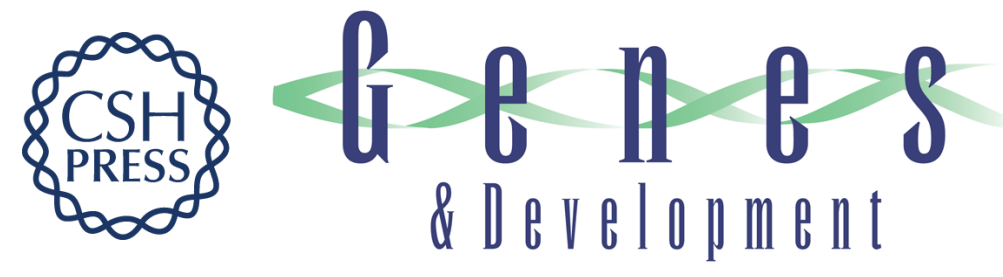

\section{$\kappa$ chain monoallelic demethylation and the establishment of allelic exclusion}

Raul Mostoslavsky, Nandita Singh, Andrei Kirillov, et al.

Genes Dev. 1998, 12:

Access the most recent version at doi:10.1101/gad.12.12.1801

References

This article cites 52 articles, 16 of which can be accessed free at: http://genesdev.cshlp.org/content/12/12/1801.full.html\#ref-list-1

\section{License}

Email Alerting

Receive free email alerts when new articles cite this article - sign up in the box at the top Service right corner of the article or click here.

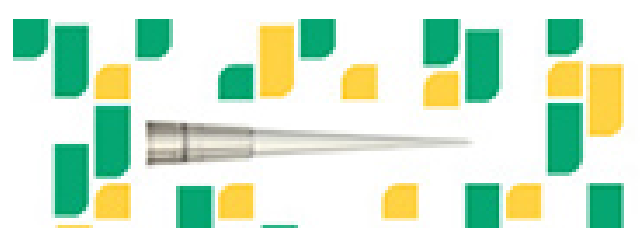

Focused on your science. 